\title{
RESEARCH
}

Open Access

\section{The abnormal lipid profile in obesity and coronary heart disease (CHD) in Pakistani subjects}

Shabana*, Saleem Ullah Shahid and Sumbal Sarwar

\begin{abstract}
Background: Obesity has become global epidemic in the last three decades, whereas Coronary Heart Disease (CHD) still remains the most important cause of mortality in the world. The study was aimed at determining the pattern of lipid profile for the obese and CHD population in Pakistan. As obesity is a strong predisposing risk factor for $\mathrm{CHD}$, we aimed to analyze the lipid parameters in both conditions and compare them with the healthy controls of the same ethnicity.
\end{abstract}

Methods: Blood samples were collected from one thousand individuals (500 with CHD, 250 with obesity, 250 healthy controls). The lipid profile (total Cholesterol, triglycerides, HDL-C, LDL-C and VLDL) was measured using commercially available kits. The pattern of dyslipidemia was then studied by comparing the results in both groups with controls as well as population cutoffs. The quantitative variables were checked for normality and log transformation was done for variables where appropriate. Analysis of variance and logistic regression were done to check the association of lipid parameters with obesity and CHD.

Results: The obese and CHD groups showed a dyslipidemic profile than the healthy controls. CHD group had a higher proportion of CHD in any of the first degree blood relatives (36.0\% vs. 1.8\%), a similar trend was observed in the obese group, where $63.9 \%$ cases had positive family history. Among cases, 50.7\% had combined lipid abnormalities, i.e., the values of TC, LDL-C, TG and HDL-C, all were deranged. Whereas $49.52 \%$ had TC more than normal cut off (> $200 \mathrm{mg} / \mathrm{dl}$ ), 51.6\% had LDL-C > $100 \mathrm{mg} / \mathrm{dl}$. Similarly, 80.4\% of patients had TG levels more than upper normal range $(>150 \mathrm{mg} / \mathrm{dl})$ and $64 \%$ had $\mathrm{HDL}$ values in moderate CHD risk group $(<50 \mathrm{mg} / \mathrm{dl})$. The results show that Pakistani cases are hyperlipidemic for lipid traits except for HDL which is lowered. Patients with comorbidities also had lipid profiles deviated from the normal range.

Conclusion: The study provides information regarding the aberration of lipid profile in the metabolic disorders that can increase the predisposition to complications.

Keywords: Dyslipidemia, Obesity, Epidemic, Lipid profile, Coronary heart disease

* Correspondence: shabana.mmg@pu.edu.pk

Department of Microbiology and Molecular Genetics, University of the

Punjab, Lahore 54690, Pakistan

C C The Author(s). 2020 Open Access This article is licensed under a Creative Commons Attribution 4.0 International License, which permits use, sharing, adaptation, distribution and reproduction in any medium or format, as long as you give appropriate credit to the original author(s) and the source, provide a link to the Creative Commons licence, and indicate if changes were made. The images or other third party material in this article are included in the article's Creative Commons licence, unless indicated otherwise in a credit line to the material. If material is not included in the article's Creative Commons licence and your intended use is not permitted by statutory regulation or exceeds the permitted use, you will need to obtain permission directly from the copyright holder. To view a copy of this licence, visit http://creativecommons.org/licenses/by/4.0/ The Creative Commons Public Domain Dedication waiver (http://creativecommons.org/publicdomain/zero/1.0/) applies to the data made available in this article, unless otherwise stated in a credit line to the data. 


\section{Introduction}

Obesity is defined as having an excess of body weight. A World Health Organization (WHO) release defined obesity as a chronic disease increasing globally replacing traditional health concerns [1]. It is directly related to cardiovascular problems and children whose parents are cardiovascular patients tend to have higher weight in the childhood and develop obesity as adults [2]. Coronary heart disease (CHD) has been estimated to become the leading cause of death in developing countries by 2020 [3]. More than $80 \%$ of global CHD burden occurs in low income countries but the knowledge regarding important risk factors is derived largely from developed countries. There is geographic variability in the prevalence of CHD risk factors [4] and it is important to use the local data when discussing the relation between a disease and its risk factors,. It is still unclear to what extent the CHD risk factors known in the western civilizations are applicable in Pakistan. One possible reason is the high prevalence of CHD risk factors like hypertension, obesity and dyslipidemia in Pakistan [5]. Considering obesity as $\mathrm{CHD}$ risk factor, it has been shown that increased abdominal obesity, insulin resistance and type 2 diabetes (T2DM) are more prevalent in South Asians and are important CHD risk factors [6]. As CHD can be a sequel of obesity, the biochemical pathways involved in the development of obesity have also been investigated to play a role in the development of CHD [7].

Blood lipid levels are modifiable risk factors for atherosclerosis and CHD. Being hydrophobic in nature, cholesterol, cholesterol esters, triglycerides and phospholipids are transported to the other tissues in the form of lipoproteins. Major classes of lipoproteins are chylomicrons (CM), low density lipoproteins (LDL) and high density lipoproteins (HDL), named by the site of their assembly and type of lipid and apo protein they have [8]. Excess fatty acids (FA) in the liver are converted into triacyglycerols which along with phospholipids, free and esterified cholesterol are packaged into very low density lipoprotein (VLDL) along with a variety of apo proteins. While travelling through the peripheral tissues, triacyglycerol content is hydrolysed with the help of lipoprotein lipase (LPL) into FA and VLDL remnants [9]. VLDL remnants through further hydrolysis of triglyceride contents give rise to intermediate density lipoproteins (IDL) and LDL. LDL having apoB100 apo protein component is the major cholesterol carrier in peripheral circulation [10]. Elevated plasma levels of these non HDL lipoproteins are major CHD risk factors [11].

It has been observed that many lipid/lipoprotein abnormalities are prevalent in obesity and heart problems, collectively termed as dyslipidemia, however, these dyslipidemias are often hyperlipidemia wherein majority of lipids are shifted towards the upper limits of range or higher than the range. Owing to the recent modernization of the lifestyle and availability of transportation means combined with a unique ethnicity have resulted in the high prevalence of metabolic disorders in Pakistan like the rest of the world. This not only affects the daily activities, work performance and social interactions but also poses a huge burden on healthcare. Keeping in view the importance of lipid traits in the development of nutritional disorders, the current study was conducted to investigate the lipid profile patterns in the obese and CHD patients in Pakistani subjects.

\section{Materials and methods}

\section{Study design, subjects selection and evaluation criteria}

The study followed a case-control study design and was performed at the Department of Microbiology and Molecular Genetics, University of the Punjab, Lahore. It included $500 \mathrm{CHD}$ patients, 250 obese and 250 age and sex matched controls. The patients were recruited from various hospitals of Punjab. The patients come from not only various cities and villages of Punjab but also from all over Pakistan to these government hospitals, therefore the samples were representative of the majority of the population. The selected CHD subjects had suffered from a non-fatal myocardial infarction with diagnosis made by the consultant cardiologist based on the reports of ECG, cardiac echo, angiography, troponine $\mathrm{T} / \mathrm{I}$ and clinical history. Only those CAD cases were selected which were recently diagnosed and had not started lipid lowering or antihypertensive drugs therapy.. The inclusion criteria for obese subjects was based on BMI cut offs defined for Asian populations previously $\left(\mathrm{BMI}>23 \mathrm{Kg} / \mathrm{m}^{2}\right.$ as overweight and $>26 \mathrm{Kg} / \mathrm{m}^{2}$ as obese) $[12,13]$. Waist to hip ratio was used as an indirect indication of upper and lower body fat distribution [14].. The controls were apparently healthy subjects having BMI 18 and 23 and not having any CHD history. No underweight subject, pregnant women, persons with malignancies/infections were included in the study, also CHD subjects with obesity were excluded. The presence of comorbidities (diabetes, hypertension) was identified. Diabetes was indicated by fasting blood glucose (FBG) of $6.7 \mathrm{mmol} / \mathrm{L}$ or above or a $2 \mathrm{~h}$ postprandial blood glucose of 11.1 $\mathrm{mmol} / \mathrm{L}$ or above. The criteria for classification of hypertensive and normotensive individuals was based on report from seventh Joint National Committee for Hypertension (JNC-V) [15]. Blood pressure measurements were taken by a trained health professional after the subject had a $5 \mathrm{~min}$ sitting. The study was approved by the institutional ethical committee (Ethical Committee, School of Biological Sciences, University of the Punjab). 


\section{Sample collection}

$5 \mathrm{ml}$ overnight fasting blood were collected in a vacutainer contining gel clot activator from the median cubital vein with tourniquet tied to the limb and fingers squeezed. Blood was centrifuged for $10 \mathrm{~min}$ at $10,000 \mathrm{rpm}$ to settle all the formed elements and separate serum. Serum was transferred to an autoclaved eppendorf and were immediately frozen until further analyses.

\section{Lipid profile estimation}

Plasma lipids and lipoprotein variables, namely total cholesterol (TC), and triglycerides (TG), were determined using commercially available kits (Spectrum Diagnostics). All optical density measurements were made using Epoch Biotek (SN 257866, USA) at $546 \mathrm{~nm}$ for TC and TG. High density lipoprotein cholesterol (HDL-C), and low density lipoprotein cholesterol (LDL-C) were measured according to Mohsen Ibrahim et al [16]. HDL determination required precipitation of very low density lipoprotein (VLDL) and low density lipoprotein (LDL) particles first from serum, while what is left in serum is HDL-C which is then detected on the same principle as total cholesterol. LDL-C determination makes use of a modified polyvinyl sulfonic acid (PVS) and polyethyleneglycol methyl ether (PEGME) coupled classic precipitation method. PVS and PEGME react with LDL, VLDL, and chylomicron $(\mathrm{CM})$ resulting in inaccessibility of these particles by cholesterol oxidase (CHOD) and cholesterol esterase (CHER), whereas HDL reacts with the enzymes. Addition of a second detergent containing reagent releases LDL from the PVS/PEGME complex. The released LDL then reacts with the enzymes to produce $\mathrm{H}_{2} \mathrm{O}_{2}$ which is quantified by the Tinder reaction.

\section{Statistical analysis}

Data was analyzed for means and standard deviation for all parameters. Data analysis was done by Microsoft excel and statistical package for social sciences (SPSS version 22). The lipid profile parameters were checked for normality. The association of lipid profile parameters with the CHD/Obese status was checked using binary logistic regression analysis using $\mathrm{CHD} /$ obese status as dependent and lipid traits as independent variables. The one-way analysis of variance (ANOVA) was done to compare the means of different groups. The analyses were adjusted for confounders including age, gender, socioeconomic status (SES), the hypertensive and diabetic status while analyzing the association with $\mathrm{CHD}$ and obese status. A $p$-value $<0.05$ was considered statistically significant for all analyses.

\section{Results}

In total, one thousand subjects were included in the study. The mean age of CHD group was $59.1 \pm 12.7$, for obese group $39.63 \pm 15.19$ and for the controls $55.8 \pm$ 10.3. The demographic characteristics of controls, and obese and CHD cases are summarized in Table 1.

As far as the blood lipid levels are concerned, patients were more dyslipidemic than the healthy controls. Mean TC, TG, high density lipoprotein cholesterol (HDL-C), low density lipoprotein cholesterol (LDL-C), and TC/ HDL ratios are shown in the Table 2. The mean TC, TG and LDL-C were significantly higher and HDL-C was significantly lower in the cases as compared to the controls. The TC/HDL-C ratio, which is considered to be a sensitive indicator of cardiovascular disease risk, was also higher in the cases, obese as well as CHD, than the controls, and the difference was statistically significant. CHD had also association with a history of CHD in any

Table 1 Baseline characteristics of the population under study. Categorical variables are expressed in number in percentage; $p$ is the statistically significant value

\begin{tabular}{|c|c|c|c|c|c|}
\hline \multirow[t]{2}{*}{ Variables } & \multicolumn{2}{|l|}{ Cases } & \multirow[t]{2}{*}{ Controls } & \multirow{2}{*}{$\begin{array}{l}\boldsymbol{p} \text {-value } \\
\text { CHD vs } \\
\text { Controls }\end{array}$} & \multirow{2}{*}{$\begin{array}{l}\boldsymbol{p} \text {-value } \\
\text { Obese vs } \\
\text { Controls }\end{array}$} \\
\hline & $\overline{\mathrm{CHD}}$ & Obese & & & \\
\hline Number & 500 & 250 & 250 & - & - \\
\hline Age & $59 \pm 12.7$ & $39.6 \pm 15.19$ & $55.87 \pm 10.37$ & 0.002 & $3.2 \times 10^{-57}$ \\
\hline \multicolumn{6}{|l|}{ Gender } \\
\hline Males (\%) & 58.2 & 54 & 55.4 & 0.49 & 0.131 \\
\hline Females (\%) & 41.8 & 46 & 44.6 & & \\
\hline Diabetic (\%) & 64.3 & 32 & 13.4 & $<0.0001$ & $<0.0001$ \\
\hline Hypertension (\%) & 59.9 & 25.6 & 16.2 & $<0.0001$ & $<0.0001$ \\
\hline Smoking (\%) & 29.4 & 11.9 & 10.3 & $<0.0001$ & $<0.0001$ \\
\hline Family history (\%) & $\begin{array}{l}36.0 \\
\text { (FH of } \mathrm{CHD})\end{array}$ & $\begin{array}{l}63.9 \\
\text { (FH of Obesity) }\end{array}$ & $\begin{array}{l}1.8 \text { (CHD) } \\
8.4 \text { (Obesity) }\end{array}$ & $<0.0001$ & $<0.0001$ \\
\hline BMI $\left(\mathrm{Kg} / \mathrm{m}^{2}\right)$ & $22.4 \pm 6.7$ & $36.9 \pm 6.4$ & $21.4 \pm 9.1$ & $<0.0001$ & $<0.0001$ \\
\hline WHR & $0.85 \pm 0.06$ & $1.00 \pm 0.09$ & $0.85 \pm 0.10$ & 1 & $<0.0001$ \\
\hline
\end{tabular}


Table 2 Blood lipid levels of the patients and controls under study

\begin{tabular}{|c|c|c|c|c|c|c|}
\hline Variable & $\mathrm{CHD}$ & Obese & Controls & $\begin{array}{l}\boldsymbol{p} \text {-value } \\
\text { CHD vs Controls }^{\mathrm{a}}\end{array}$ & $\begin{array}{l}\boldsymbol{p} \text {-value } \\
\text { Obese vs Controls }\end{array}$ & $\begin{array}{l}\boldsymbol{p} \text {-value } \\
\text { ANOVAC }\end{array}$ \\
\hline $\mathrm{TC}(\mathrm{mg} / \mathrm{dl})$ & $208.2 \pm 54.11$ & $214.4 \pm 35.02$ & $158.6 \pm 33.14$ & $2.9 \times 10^{-23}$ & $2.4 \times 10^{-36}$ & $<0.001$ \\
\hline $\mathrm{TG}(\mathrm{mg} / \mathrm{dl})$ & $214.5 \pm 74.60$ & $265.1 \pm 50.38$ & $187.7 \pm 41.75$ & $2.09 \times 10^{-34}$ & $1.8 \times 10^{-7}$ & $<0.001$ \\
\hline HDL-C (mg/dl) & $45.1 \pm 11.63$ & $43.1 \pm 4.23$ & $80.6 \pm 12.71$ & $1.06 \times 10^{-71}$ & $1.6 \times 10^{-179}$ & $<0.001$ \\
\hline LDL-C (mg/dl) & $104.6 \pm 37.94$ & $115.7 \pm 21.99$ & $78.1 \pm 15.42$ & $1.6 \times 10^{-34}$ & $1.3 \times 10^{-24}$ & $<0.001$ \\
\hline TC/HDL-C & $4.6 \pm 0.87$ & $5.0 \pm 0.97$ & $2.7 \pm 1.11$ & $1.6 \times 10^{-34}$ & $3.8 \times 10^{-98}$ & $<0.001$ \\
\hline
\end{tabular}

Continuous variables are expressed in mean \pm SD

$T C$ total cholesterol level, VLDL very low density lipoprotein concentration, $L D L-C$ low density lipoprotein cholesterol level, $H D L-C$ high density lipoprotein level and TG: triglycerides level

aindicates the significance of difference between the means of CHD vs controls

${ }^{b}$ indicates the significance of difference between the means of Obeses vs controls

cindicates the significance of difference between means of all groups as tested by ANOVA

of the first degree blood relatives in the family $(36.0 \%$ vs. $1.8 \%$ ), a similar trend was observed in the obese group where $63.9 \%$ cases had a family history of obesity.

In the cases, the proportion of males suffering from the disease was higher than females ( $57 \%$ vs $42.8 \%$ ). The mean age was slightly higher in female patients than male patients $(59.5 \%$ vs $58.5 \%)$. The percentage of diabetes was also higher in males than females. However, among CHD females, the ratio of hypertension was more than males and family history of having CHD was also higher in females than male patients. However, these differences were not statistically significant; the only significant difference between male and female patients was their smoking status, which was present almost exclusively in males (50\%) and only $0.6 \%$ females were smokers ang CHD whereas in the obese group, the proportion of smokers was low compared to the CHD group as well as smoking did not appear to be associated with obesity.

Lipid abnormalities were present individually as well as in combination. Among the cases (CHD and obese combined), $50.7 \%$ had combined lipid abnormalities, i.e., the values of TC, LDL-C, TG and HDL-C were all deranged. Whereas $49.5 \%$ had TC more than normal cut off ( $>200 \mathrm{mg} / \mathrm{dl}), 51.6 \%$ had LDL-C $>100 \mathrm{mg} /$ dl. Similarly, $80.4 \%$ of patients had TG levels more than upper normal range $(>150 \mathrm{mg} / \mathrm{dl})$ and $64 \%$ had HDL values in moderate CHD risk group $(<50 \mathrm{mg} / \mathrm{dl})$ (Table 3).

Table 3 Genderwise presentation of subjects in the CHD and obese group showing deranged Lipid Profile

\begin{tabular}{|c|c|c|c|c|}
\hline \multirow{2}{*}{$\begin{array}{l}\text { Variables } \\
\text { (mg/dl) }\end{array}$} & \multicolumn{2}{|l|}{$\mathrm{CHD}$} & \multicolumn{2}{|l|}{ Obese } \\
\hline & Males & Females & Males & Females \\
\hline TC > 199 & $51.5 \%(124)$ & $50.3 \%(87)$ & $44.7 \%$ (114) & $45 \%$ (99) \\
\hline$T G>1$ & $78.8 \%$ (190) & $82.1 \%(142)$ & $86.6 \%$ (221) & $85 \%$ (187) \\
\hline HDL-C $<40$ & $45.5 \%(110)$ & $53.8 \%(93)$ & $48.2 \%(123)$ & $53.6 \%(111)$ \\
\hline 49 & $65.6 \%(158)$ & $55.1(96)$ & $50.9 \%(130)$ & 54.9 (114) \\
\hline LDL-C > 99 & $50.6 \%(122)$ & $56.1 \%(97)$ & $54.1 \%(138)$ & $50.4 \%(118)$ \\
\hline
\end{tabular}

The comparison of the means of the lipid profile parameters between males and females turned out that among the CHD males/females as well as obese males/ females, no significant difference was observed (Table 4). However, the logistic regression analysis of all the parameters with $\mathrm{CHD} /$ obese status turned out to be highly significant (Table 5).

\section{Discussion}

Abnormalities in the lipid profile, specifically hypertriglyceridemia and low levels of HDL-C have been shown to be a strong predisposing issue to many diseases including obesity, diabetes and cardiovascular diseases. It has been estimated that the risk of CVD decreases by 2 to $3 \%$ for every $1 \mathrm{mg} / \mathrm{dL}$ increase in HDL-C [17]. Despite some controversy, elevated levels of triglycerides, fasting as well as nonfasting, also appear to be an independent risk factor for CHD [18, 19]. Evidence from epidemiologic studies suggests that the co-occurrence of low HDL-C and elevated triglyceride levels is a strong risk factor for CHD [20, 21] while posthoc analyses of several studies have shown that patients with low HDL-C and elevated triglycerides have the highest rate of major coronary events [22]. Whether an increased level of small dense LDL represents an independent risk factor remains somewhat controversial, but it is clearly associated with an increase in CHD risk [23]. Serum cholesterol has been shown to be an established CHD risk factor in European people [24] as well as Asians [25] Elevated levels of plasma LDL-C are major CHD risk factors as therapy with LDL-C drugs have reduced CHD risk and the reduction is proportion to decrease in LDL-C levels [26, 27].

As expected, already established obesity and CHD risk factors had a high prevalence in the patients in the current study as well. It was clear that lipid profile of patients was more atherogenic and patients exhibited significantly higher prevalence of other CHD risk factors 
Table 4 Lipid profile values of the Cases (CHD \& obese) separated by their gender status

\begin{tabular}{|c|c|c|c|c|c|c|}
\hline \multirow[t]{2}{*}{ Variable } & \multicolumn{2}{|l|}{$\mathrm{CHD}$} & \multirow{2}{*}{$\begin{array}{l}P \\
\text { value }\end{array}$} & \multicolumn{2}{|l|}{ Obese } & \multirow{2}{*}{$\begin{array}{l}P \\
\text { value }\end{array}$} \\
\hline & Males & Females & & Males & Females & \\
\hline $\mathrm{TC}(\mathrm{mg} / \mathrm{dl})$ & $208.5 \pm 54.6$ & $207.7 \pm 53.5$ & 0.88 & $199.5 \pm 45.1$ & $192.2 \pm 43.4$ & 0.074 \\
\hline TG (mg/dl) & $213.2 \pm 75.6$ & $216.2 \pm 73.2$ & 0.69 & $237.6 \pm 67.1$ & $226.2 \pm 62.9$ & 0.056 \\
\hline HDL-C (mg/dl) & $44.2 \pm 11.2$ & $46.3 \pm 12.1$ & 0.07 & $55.1 \pm 17.3$ & $54.7 \pm 18.0$ & 0.839 \\
\hline LDL-C (mg/dl) & $104.8 \pm 39.9$ & $104.2 \pm 35.1$ & 0.87 & $103.7 \pm 29.2$ & $98.7 \pm 27.4$ & 0.056 \\
\hline
\end{tabular}

like hypertension, DM and smoking compared to age and sex matched controls. The findings are in accordance with another Pakistani study and the studies carried out in other developed countries [28-30].

High percentage of males was found to be suffering from the disease than females. This does not seem to be by chance, rather shows increased prevalence of the disease among males in the selected study group as well as the general population. Similar results were seen in another study conducted in Pakistan [31]; however the reports of some other researchers [5, 32] were contradictory. Secondary causes, such as high values for mean TC, LDL-C, smoking rate, DM and low values for $\mathrm{HDL}-\mathrm{C}$ in males than females may be due to higher prevalence in males than females. This may also lead to altered lipid profile between females and males.

Hypercholesterolemia, either genetic or acquired, is an independent CHD risk factor. It is estimated that $56 \%$ of the total heart diseases may be due to hypercholesterolemia (> $200 \mathrm{mg} / \mathrm{dl}$ ) alone [31]. It was observed that patients had significantly higher TC levels, also hypercholesterolemia was heterogeneous within patients as hypertensive males were having high cholesterol levels than normotensive $(p=0.006)$ and diabetic females were having high cholesterol than non diabetic $(p=0.00004)$. Non diabetic females were having the lowest cholesterol levels among cases. This indicates that cholesterol levels are also being affected by diabetes and the lipid profile is more disturbed in subjects who have other metabolic conditions. Many authors have reported the lipid levels to be similar among Asian and western countries and attributed the increased risk of $\mathrm{CHD}$ to be due to insulin resistance and central obesity $[4,33,34]$.

TC/HDL ratio is considered to be a sensitive predictor of cardiovascular disease risk, especially if the values are $\geq 6$ [35-37]. Although in our study, the TC/HDL ratio is significantly higher than controls, the values are below this cutoff. In the USA, however, the TC / HDL ratio above 5 is considered to be atherogenic. Interestingly, using this cutoff, we noticed a gender difference in the patterns of dyslipidemia among diabetic and non diabetic groups. Among diabetics, the mean ratio for males, 5.22 is higher than the USA cut off while females had a ratio, 4.88 below the cut-off. On the contrary, in the nondiabetic group, females had a ratio, 5.08, higher than the cutoff while males had a mean ratio, 4.89, lower than the cutoff.

In the current study, increased TG concentrations are consistently accompanied by low HDL concentrations that often coexists with the elevated plasma glucose levels because high amount of sugar in plasma (hyperglycemia) results in the transfer of cholesterol esters from HDL-C to VLDL particles [38]. Further lowering in HDL concentration results from its conversion by hepatic lipase into smaller particles which are rapidly cleared from plasma [39]. Resulting VLDL particles form cholesteryl ester depleted small dense LDL-C particles that are taken up by arterial wall macrophages causing atherogenesis [40].

The study had limitation of small sample size. The sample size of one thousand is not sufficient to rule out any minor gender related differences. The coexistence of several conditions (obesity, diabetes, hypertension, cardiovascular diseases) further complicates the analyses. Despite these limitations, the study gives basic information about dyslipidemia in obese and CHD population in Pakistan and can be helpful in advanced research about lipid profile and establishing a correlation between lipid profile parameters and dyslipidemia associated abnormalities in Pakistani population.

Table 5 Logistic regression model for CHD/Obese status

\begin{tabular}{|c|c|c|c|c|}
\hline \multirow[t]{2}{*}{ Variable } & \multicolumn{2}{|l|}{$\mathrm{CHD}$} & \multicolumn{2}{|l|}{ Obese } \\
\hline & OR $(95 \% \mathrm{Cl})$ & $p$-value & OR $(95 \% \mathrm{Cl})$ & $p$-value \\
\hline $\mathrm{TC}(\mathrm{mg} / \mathrm{dl})$ & $2.18(1.76-2.71)$ & $<0.0001$ & $1.02(1.01-1.03)$ & $<0.0001$ \\
\hline TG (mg/dl) & $1.42(1.19-1.69)$ & $<0.0001$ & $1.113(1.09-1.136)$ & $<0.0001$ \\
\hline HDL-C (mg/dl) & 7.07 (5.14-9.71) & $<0.0001$ & $0.814(0.778-0.853)$ & $<0.0001$ \\
\hline LDL-C (mg/dl) & $2.79(2.22-3.50)$ & $<0.0001$ & $1.037(1.02-1.05)$ & $<0.0001$ \\
\hline
\end{tabular}




\section{Conclusion}

The study showed that dyslipidemia is an important factor contributing to the development of obesity and CHD in Pakistan. The study provides information regarding the importance of considering the lipid profiling in the treatment of these metabolic disorders. Apparently healthy individuals should get their lipid profiling done once or twice a year and go for appropriate lifestyle changes so as to prevent the onset of metabolic aberrations. The recent westernized lifestyle in the Pakistani youth combined with the inherent tendency of fat deposition in the abdominal area has increased the risk of obesity and its sequelae. In these situations, a simple lipid profile test can help manage the dyslipidemia before the onset of disease.

\section{Abbreviations}

CHD: Coronary heart disease; HDLC: high-density lipoprotein cholesterol; LDL-C: Low-density lipoprotein cholesterol; TC: Total cholesterol; TG: Triglycerides; WHO: World Health Organization; LPL: lipoprotein lipase; JNC$\checkmark$ : Joint National Committee for Hypertension

\section{Acknowledgments}

This work was supported by the University of the Punjab Lahore, Pakistan. The authors are obliged to all volunteer family members for their valuable participation in the present study.

\section{Authors' contributions}

SUS, designed the study, assisted in sample collection, SS helped in performing experiments, assisted in statistical analysis and manuscript writing. Shabana designed and supervised the study, reviewed the paper and provided technical support. All authors have read and approved the final manuscript.

\section{Funding}

University of the Punjab provided the financial support for the study.

\section{Availability of data and materials}

All the necessary information has been provided along with the manuscript, however, the corresponding author can be contacted for any information related to this paper.

\section{Ethics approval and consent to participate}

The study protocol for human subjects was approved by the ethics committee (Ethical Committee, School of Biological Sciences SBS) of University of the Punjab.

\section{Consent for publication}

There is no conflict of interests regarding the publication of this article.

\section{Competing interests}

The authors declare that they have no competing interests.

Received: 14 September 2019 Accepted: 31 March 2020

Published online: 14 April 2020

\section{References}

1. Javed A, Jumean M, Murad M, Okorodudu D, Kumar S, Somers V, et al. Diagnostic performance of body mass index to identify obesity as defined by body adiposity in children and adolescents: a systematic review and meta-analysis. Pediatric Obesity. 2014;10(3):234-44.

2. Klatzkin RR, Gaffney S, Cyrus K, Bigus E, Brownley KA. Binge eating disorder and obesity: preliminary evidence for distinct cardiovascular and psychological phenotypes. Physiol Behav. 2015;145(1):20-7.

3. Organization $\mathrm{WH}$. The double burden: emerging epidemics and persistent problems. Switzerland: The world health report; 1999. p. 221-7.
4. Yusuf S, Hawken S, Ônpuu S, Dans T, Avezum A, Lanas F, et al. Effect of potentially modifiable risk factors associated with myocardial infarction in 52 countries (the INTERHEART study): case-control study. Lancet. 2004; 364(9438):937-52.

5. Awan ZA, Gul AM, Sahibzada WA, Hafizullah M. Prevalence of coronary artery disease in rural areas of Peshawar. J Postgraduate Med Inst (Peshawar-Pakistan). 2011;19(1):14-22.

6. Raji A, Seely EW, Arky RA, Simonson DC. Body fat distribution and insulin resistance in healthy Asian Indians and Caucasians. J Clin Endocrinol Metab. 2001;86(11):5366-71.

7. Flegal KM, Graubard BI, Williamson DF, Gail MH. Cause-specific excess deaths associated with underweight, overweight, and obesity. Obstet Gynecol Surv. 2008;63(3):157-9.

8. Chen J, Corbin I, Zhang Z, Zheng G. High-density lipoprotein-like peptidephospholipid scaffold ('hpps') nanoparticles. Canada: US Google Patents; 2009

9. Maxfield FR, Tabas I. Role of cholesterol and lipid organization in disease. Nature. 2005:438(7068):612-21.

10. Packard C. Triacylglycerol-rich lipoproteins and the generation of small, dense low-density lipoprotein. Biochem Soc Trans. 2003;31(5):1066-9.

11. Cohen JC, Boerwinkle E, Mosley TH Jr, Hobbs HH. Sequence variations in PCSK9, low LDL, and protection against coronary heart disease. New Engl J Med. 2006:354(12):1264-72.

12. Mascie-Taylor CN, Goto R. Human variation and body mass index: a review of the universality of BMI cut-offs, gender and urban-rural differences, and secular changes. J Physiol Anthropol. 2007;26(2):109-12.

13. Yusuf S, Hawken S, Ônpuu S, Bautista L, Franzosi MG, Commerford P, et al. Obesity and the risk of myocardial infarction in 27000 participants from 52 countries: a case-control study. Lancet. 2005;366(9497):1640-9.

14. Sandhu HS, Koley S, Sandhu KS. A study of correlation between lipid profile and waist to hip ratios in patients with diabetes mellitus. Anthropologist. 2008;10(3):215-8.

15. Chobanian AV, Bakris GL, Black HR, Cushman WC, Green LA, Izzo JL, et al. Seventh report of the joint national committee on prevention, detection, evaluation, and treatment of high blood pressure. Hypertension. 2003;42(6): 1206-52.

16. Mohsen Ibrahim M, Ibrahim A, Shaheen K, Nour MA. Lipid profile in Egyptian patients with coronary artery disease. Egyptian Heart J. 2012;65(2):79-85.

17. Turner R, Millns H, Neil H, Stratton I, Manley S, Matthews D, et al. Risk factors for coronary artery disease in non-insulin dependent diabetes mellitus: United Kingdom prospective diabetes study (UKPDS: 23). BMJ. 1998; 316(7134):823-8.

18. Eberly LE, Stamler J, Neaton JD. Relation of triglyceride levels, fasting and nonfasting, to fatal and nonfatal coronary heart disease. Arch Intern Med. 2003;163(9):1077-83.

19. Bansal S, Buring JE, Rifai N, Mora S, Sacks FM, Ridker PM. Fasting compared with nonfasting triglycerides and risk of cardiovascular events in women. JAMA. 2007;298(3):309-16.

20. Jeppesen J, Hein HO, Suadicani P, Gyntelberg F. Relation of high TG-low HDL cholesterol and LDL cholesterol to the incidence of ischemic heart disease an 8-year follow-up in the Copenhagen male study. Atertio Thromb Vasc Biol. 1997;17(6):1114-20

21. Assmann G, Schulte H. Relation of high-density lipoprotein cholesterol and triglycerides to incidence of atherosclerotic coronary artery disease (the PROCAM experience). Am J Cardiol. 1992:70(7):733-7.

22. Ballantyne CM, Olsson AG, Cook TJ, Mercuri MF, Pedersen TR, Kjekshus J. Influence of low high-density lipoprotein cholesterol and elevated triglyceride on coronary heart disease events and response to simvastatin therapy in 4S. Circulation. 2001:104(25):3046-51.

23. Sacks FM, Campos H. Clinical review 163: cardiovascular endocrinology: lowdensity lipoprotein size and cardiovascular disease: a reappraisal. J Clin Endocrinol Metab. 2003;88(10):4525-32.

24. Stamler J, Daviglus ML, Garside DB, Dyer AR, Greenland P, Neaton JD. Relationship of baseline serum cholesterol levels in 3 large cohorts of younger men to long-term coronary, cardiovascular, and all-cause mortality and to longevity. JAMA. 2000;284(3):311-8.

25. Chen Z, Peto R, Collins R, MacMahon S, Lu J, Li W. Serum cholesterol concentration and coronary heart disease in population with low cholesterol concentrations. BMJ. 1991;303(6797):276-82. 
26. Unit ES. Efficacy and safety of cholesterol-lowering treatment: prospective meta-analysis of data from 90056 participants in 14 randomised trials of statins. Lancet. 2005;366(9493):1267-78.

27. de Lemos J, Braunwald E, Blazing M, Murphy S, Downs J, Gotto A, et al. Efficacy and safety of more intensive lowering of LDL cholesterol: a metaanalysis of data from 170,000 participants in 26 randomised trials. Lancet. 2010;376(9753):1670-81.

28. Kwiterovich PO Jr, Coresh J, Bachorik PS. Prevalence of hyperapobetalipoproteinemia and other lipoprotein phenotypes in men (aged $\leq 50$ years) and women ( $\leq 60$ years) with coronary artery disease. Am J Cardiol. 1993;71(8):631-9.

29. Genest J, Martin-Munley SS, McNamara JR, Ordovas JM, Jenner J, Myers RH, et al. Familial lipoprotein disorders in patients with premature coronary artery disease. Circulation. 1992;85(6):2025-33.

30. Lamarche B, Moorjani S, Cantin B, Dagenais GR, Lupien P-J. Prevalence of dyslipidemic phenotypes in ischemic heart disease (prospective results from the Que' bec cardiovascular study). Am J Cardiol. 1995;75(17):1 189-95.

31. Abbas S, Kitchlew A, Abbas S. Disease burden of ischemic heart disease in Pakistan and its risk factors. Ann Pak Inst Med Sci. 2009:5(3):145-50.

32. Aziz KU, Faruqui A, Patel N, Jaffery $\mathrm{H}$. Prevalence and awarenes of cardiovascular disease including life styles in a lower middle class urban community in an Asian country. Pakistan Heart J. 2012;41 (4):11-20.

33. Collaboration APCS. Cholesterol, coronary heart disease, and stroke in the Asia Pacific region. Int J Epidemiol. 2003;32(4):563-72.

34. Gupta M, Brister S, Verma S. Is south Asian ethnicity an independent cardiovascular risk factor? Can J Cardiol. 2006;22(3):193-7.

35. Gordon L, Ragoobirsingh D, St Errol Y, Choo-Kang E, McGrowder D, Martorell E. Lipid profile of type 2 diabetic and hypertensive patients in the Jamaican population. J Lab Physicians. 2010;2(1):25.

36. Genest J, Frohlich J, Fodor G, McPherson R. Recommendations for the management of dyslipidemia and the prevention of cardiovascular disease: summary of the 2003 update. Can Med Assoc J. 2003;169(9):921-4.

37. Laakso M. Dyslipidemia, morbidity, and mortality in non-insulin-dependent diabetes mellitus: lipoproteins and coronary heart disease in non-insulindependent diabetes mellitus. J Diabetes Complicat. 1997;11(2):137-41.

38. Goldberg IJ. Diabetic dyslipidemia: causes and consequences. I Clin Endocrinol Metab. 2001;86(3):965-71.

39. Sutter I, Riwanto M, Rohrer L, Othman A, Hornemann T, Landmesser U, et al. Low concentrations of sphingosine-1-phosphates and plasmalogens in HDL are associated with coronary artery disease and reduced anti-apoptotic activity of HDL. Atherosclerosis. 2014;235(2):46.

40. Lawler PR, Akinkuolie A, Glynn R, Ridker P, Mora S. Atherogenic lipoprotein particle subclasses and residual cardiovascular risk: an analysis of the Jupiter trial. J Am Coll Cardiol. 2015;65(10):362-6.

\section{Publisher's Note}

Springer Nature remains neutral with regard to jurisdictional claims in published maps and institutional affiliations.

\section{Ready to submit your research? Choose BMC and benefit from:}

- fast, convenient online submission

- thorough peer review by experienced researchers in your field

- rapid publication on acceptance

- support for research data, including large and complex data types

- gold Open Access which fosters wider collaboration and increased citations

- maximum visibility for your research: over $100 \mathrm{M}$ website views per year

At $\mathrm{BMC}$, research is always in progress.

Learn more biomedcentral.com/submissions 